\title{
Relação entre o desempenho no vestibular e o desempenho durante o curso de graduação
}

\author{
Maelin da Silva* e Maristela Jorge Padoin**
}

\section{Resumo}

Para ingressar no ensino superior público ou privado o candidato precisa realizar um exame de ingresso, o chamado exame vestibular. A formação básica, a qual tem a função de desenvolver o educando, dando subsídios para exercer a cidadania e também para progredir no trabalho e em estudos posteriores, tem um papel muito importante para a aprovação no vestibular. Aberto aos concluintes do ensino médio e aprovados no vestibular, o ensino superior deve ser acessível a todas as pessoas no decorrer da vida. $\bigcirc$ nosso objetivo com o presente trabalho foi o de verificar se os primeiros e os últimos colocados no vestibular para o curso de ciências biológicas mantêm esses resultados durante o curso, e quais os fatores que contribuem para a continuidade ou não desse desempenho. Para coleta de dados foram aplicados questionários direcionados aos cinco primeiros e cinco últimos classificados no vestibular para o curso de ciências biológicas nas duas modalidades licenciatura e bacharelado; também foram analisados os históricos acadêmicos dos indivíduos, a fim de determinar o desempenho nas disciplinas. Para estudo dos resultados foi utilizada uma análise quantiqualitativa. Concluímos que, de maneira geral, os primeiros colocados mantêm um desempenho relativamente melhor que os últimos, e que fatores como a formação básica (ensino fundamental e médio), trabalhar durante o curso e a idade dos alunos são intimamente relacionados com o desempenho durante o mesmo. As duas turmas analisadas mostram características peculiares, e o período em que os cursos são ofertados tem papel relevante nesta diferença, pois abrange públicos muito distintos, e consequentemente reflete dados muito contrastantes. A prova de vestibular de maneira imediata separa quais são os alunos mais bem preparados dos menos preparados para a trajetória acadêmica, no entanto durante o curso outros fatores como família, emprego, formação básica, identificação com o curso determinam o desempenho destes alunos. Outras pesquisas que visem a caracterizar a condição sócioeconômica e também condições de aprendizado de cada aluno parecem ser necessárias para afirmar com exatidão que estes fatores contribuem efetivamente para um desempenho considerado bom ou ruim.

Palavras-chave: Vestibular. Ensino superior. Alunos trabalhadores.

\section{Relation between the University contest performance and the performance during the graduation course Abstract}

To enter a public or a private higher education institution the candidate must take an ingression examination, the initial call examination. The basic formation, which is responsible for developing the students skills, by giving them subsidies to exert

\footnotetext{
* Graduanda em Ciências Biológicas. E-mail: maelin_bio@hotmail.com

** Doutora em Fisiologia, UFRGS; Professora da Graduação da UNIOESTE. E-mail: mipadoin@unioeste.br
} 
the citizenship and also to improve in their jobs and future studies, has a very important role in the result of the university contest. Open to people who had finished high school and passed the examinations, higher education must be accessible to everyone during their whole lives. Our goal with this paper was to check if the first and the last ones placed in the university contest for the biology course keep the same results during the course, and what factors contribute to the continuity or not of this performance. To collect these data, questionnaires were given to the first and last five candidates classified in the vestibular contest for the two modalities of the biology course: licentiate and bachelor of biology; it also analyzed the academic descriptions of the students, in order to see their performance in the disciplines. To study the results a statistic analysis was made. We conclude that, in general, the first placed students perform better than the last ones, and reasons like basic formation (basic and average education), work and the age of the pupils are related to their performance during the course. The two analyzed groups show peculiar characteristics, and the period when the courses are offered makes a big difference, because it encloses a very distinct group, and, as a consequence, it reflects very different data. The test of the university contest immediately separates the students who are prepared to enroll the university from those who aren't, besides that, other reasons like: family, job, primary formation and identification to the course also determine the performance of these pupils. Other researches that aim to characterize the socio-economic condition and also the learning conditions of each pupil seems to be necessary to affirm that these reasons contribute to a good or bad performance.

Keywords: Vestibular. Higher education. Student workers.

\section{Relación entre el desempeño en el examen para ingreso en la universidad (vestibular) y el desempeño durante el curso de graduación Resumen}

Para ingresar en la educación superior pública o privada, el candidato necesita realizar un examen de ingreso llamado examen vestibular. La formación básica, que tiene la función de desarrollar el educando, dándole subsidios para ejercer la ciudadanía y también para progresar en el trabajo y en estudios posteriores, tiene un papel muy importante para la aprobación en la competencia de la universidad. Abierto a los concluyentes de la educación secundaria y aprobados en la competencia de la universidad, la educación superior debe ser accesible a toda la gente en el transcurso de la vida. Nuestro objetivo con el actual trabajo fue verificar si los primeros y los últimos colocados en el examen para el curso de ciencias biológicas mantienen los mismos resultados durante el curso y cuales factores contribuyen para la continuidad de ese desempeño. Fueron aplicados cuestionarios dirigidos a los cinco primeros y a los cinco últimos clasificados en la competencia para el curso de ciencias biológicas en las dos modalidades: licenciatura y bachillerato. También fueron analizados los históricos académicos de los estudiantes para determinar sus desempeños en las asignaturas del curso. Para el estudio de los resultados un análisis cuanticualitativo fue utilizado.

Concluimos que, de modo general, los primeras colocados mantuvieron un resultado 
relativamente mejor que los últimos colocados y que factores como la formación básica (educación básica y secundaria), trabajar durante el curso y la edad de los alumnos están relacionados con el desempeño durante el curso. Los dos grupos analizados presentaran características peculiares. El período de los cursos tuvieron papel relevante en esta diferencia, pues incluyó público distinto y reflejó datos contrastantes. La prueba de la competencia de la universidad distingue los alumnos más bien preparados para la trayectoria académica. Durante el curso otros factores como familia, trabajo, formación básica, identificación con el curso determinan el desempeño de esos estudiantes. Otras pesquisas que caractericen las condiciones socio-económicas y también las condiciones de aprendizaje de cada alumno parecen necesarias para afirmar con exactitud que estos factores contribuyen efectivamente para un buen o mal desempeño.

Palabras clave: Vestibulares. Enseñanza superior. Los estudiantes trabajadores.

\section{Ensino médio: preparação para formação do cidadão e estudos posteriores}

ensino médio é a ponte entre o ensino fundamental e o ensino superior. Essa condição deixa este nível de educação, segundo Domingues, Toschi e Oliveira (2000), despido de identidade própria, sendo configurado como preparação para ingresso no ensino superior. Porém tal nível de ensino contempla a formação geral do cidadão e a preparação para o trabalho.

Este grau de ensino foi definido na Lei de Diretrizes e Bases, a LDB n9394/96 (BRASIL, 1996), como a última etapa da educação básica, e tem como objetivos consolidar e aprofundar os conhecimentos adquiridos na educação fundamental, desenvolvendo a compreensão e o domínio dos fundamentos científicos e tecnológicos que presidem a produção moderna, e não apenas preparar para o vestibular.

ensino médio mais que dobrou seu número de matriculas na década de 90, e passou a atender a uma nova parcela da população, antes excluída (BACCHETTO, 2003). Este aumento no número de matrículas tem ocorrido na rede pública estadual, principalmente em cursos noturnos, evidenciando a incorporação de grupos sociais antes excluídos desse nível de ensino (DOMINGUES; TOSCHI; OLIVEIRA, 2000).

\section{Ensino Médio: escolhendo um curso superior}

aumento crescente de matrículas no ensino médio se deu principalmente na rede pública. Segundo Neves (2002), a formação básica tem função de desenvolver o educando, dando-lhe subsídios para exercer a cidadania e também para progredir no trabalho e em estudos posteriores. Neste contexto, essa etapa do ensino tem papel importante para o êxito nos exames de ingresso no ensino superior. Pesquisas demonstram que candidatos provenientes de escola pública costumam ter mais dificuldade para entrar na universidade, tendo em vista as deficiências da formação básica na rede pública de ensino.

Segundo Pinho (2001), no estado de São Paulo, a preparação propiciada por escolas estaduais e municipais de ensino médio, citado como $2^{\circ}$ grau, é insuficiente para garantir o sucesso na competição por uma vaga em um curso de concorrência elevada. Estes alunos preferem disputar uma vaga em carreiras menos procuradas pelos egressos das escolas particulares. Entretanto, mesmo nestes cursos, os 
ingressantes na universidade têm uma participação percentual reduzida. Whitaker e Fiamengue (2001) confirmam essa realidade dizendo que estudantes do ensino médio público optam por cursos de menor prestigio social, tanto em turnos matutino quanto no noturno, pois almejam maior sucesso na conquista da vaga.

Alunos concluintes do ensino médio em escolas privadas apresentam maiores chances na disputa por uma vaga no ensino superior. Zago (2006) considera que jovens que provêm de extratos sociais mais elevados sofrem influência dos pais para a escolha profissional, os quais possuem condições financeiras favoráveis para investir na formação dos filhos. Assim as escolhas são geralmente por cursos de maior prestigio social ou pelos que oferecem melhores oportunidades no mercado de trabalho.

Algumas carreiras escolhidas requerem dos candidatos uma sólida formação ao longo dos onze anos cobertos pelo ensino fundamental e médio. Estudos feitos por Pinho (2001) mostram que a escolha do curso feita por estudantes provenientes de escola pública é feita de modo a aumentar a probabilidade de sucesso no vestibular, mesmo que a vaga obtida não tenha grande valor no mercado de trabalho. Candidatos que provêm de ensino médio privado optam geralmente por cursos de maior prestígio, o que não significa a não-concorrência de alunos concluintes do ensino médio público. Entretanto esta diferença de preparação da educação está fortemente correlacionada com a matrícula na universidade (WHITAKER; FIAMENGUE, 2001). Braga, Peixoto e Bogutchi (2001), afirmam que o ensino superior, em especial nas universidades públicas, mostra uma relação entre o contexto social do candidato e o curso pretendido.

Um dado interessante a ser citado é que alunos que fazem parte dos estudos em escolas públicas e parte em escolas privadas, escolhem cursos concorridos, obtendo resultados intermediários (PINHO, 2001).

Mesmo em formas alternativas para a seleção de ingresso no ensino superior, a maioria esmagadora dos alunos aprovados é proveniente de escola privada, enquanto uma parcela mínima é de escola pública (BORGES; CARNIELLI, 2005).

A partir do ano 2000, com a inclusão da nota do Exame Nacional do Ensino Médio (ENEM) no resultado final das provas do vestibular da Fundação Universitária para o Vestibular (FUVEST), aumentou a procura de candidatos oriundos de escolas públicas por vagas em instituições abrangidas por este sistema de seleção. Entretanto a porcentagem de sucesso na disputa por uma vaga caiu. Dessa forma, o autor conclui que a defasagem do ensino público interfere diretamente na disputa por uma vaga (PINHO, 2001).

Vestibular: exame de ingresso no ensino superior

Para ingressar no ensino superior público ou privado, o candidato precisa realizar um exame de ingresso, o chamado exame vestibular (LEITE, 2002). Adotado pela primeira vez pela Universidade Nacional de Filosofia o exame classificatório não permitia vagas ociosas por falta de conhecimento dos candidatos, todas as cadeiras oferecidas eram preenchidas. A exigência de conhecimentos mínimos por outra forma de ingresso, a qual exigia conhecimentos mínimos, gerava ociosidade, fato que era incompatível com a grande pressão pelo ingresso (BACCHETTO, 2003). 
Desde a reformulação do ensino superior no período militar, o vestibular unificado e classificatório tem sido a forma de acesso à universidade, colocado dentro do conjunto de medidas para enfrentar o aumento da demanda observada na década de 60, e que continua até hoje (BRAGA; PEIXOTO; BOGUTCHI, 2001). Um exemplo de concurso de ingresso é o exame de seleção unificado realizado no estado de São Paulo, a Fundação Universitária para o Vestibular (FUVEST), realizada em duas fases. A primeira fase é a de conhecimentos gerais, comum para todos os candidatos, independente do curso escolhido. Esta fase é, ao mesmo tempo, eliminatória e classificatória. A segunda fase é realizada pelos candidatos aprovados na primeira, tendo uma prova composta de língua portuguesa, e mais três disciplinas selecionadas pela unidade responsável por cada curso (PINHO, 2001).

Entretanto, novas formas de avaliação para o acesso ao ensino superior vêm sendo empregadas. $\bigcirc$ vestibular seriado é uma forma alternativa de seleção para cursos de graduação oferecidos pelas instituições de educação superior, sendo um mecanismo que possibilita avaliar o aluno durante todo o ensino médio. É caracterizado por apresentar três avaliações realizadas pelos alunos, uma em cada ano letivo do ensino médio (SCHLICHTING; SOARES; BIACHENTTI, 2004). O Programa de Avaliação Seriado (PAS) da Universidade de Brasília é um exemplo deste tipo de seleção, o qual, segundo Borges e Carnielli (2005), é uma nova via de ingresso, de forma rápida ao ensino superior. Porém essa forma inovadora de selecionar candidatos, mantém a estratificação social de acesso aos cursos universitários de maior prestígio social. A Universidade Federal de Santa Maria adotou o Programa de Ingresso Superior (PEIES) e seleciona $20 \%$ de seus estudantes através desse programa. Seguindo este contexto, a Universidade Federal de Santa Catarina desde 1998 seleciona parte de seus alunos pelo Sistema de Avaliação do Ensino Médio (SAEM), e tem uma metodologia de avaliação seriada contínua e sistemática (SCHLICHTING; SOARES; BIACHENTTI, 2004). Segundo Oliveira (1987 apud BACCHETTO, 2003), essa avaliação no decorrer do ensino médio possui inúmeras vantagens quando comparada ao vestibular tradicional, pois permite ao aluno, professor e escola identificar e corrigir possíveis deficiências de ensino durante o aprendizado. Esse modelo parece diluir a tensão existente em um único exame, eliminando os cursinhos preparatórios. Este modelo ressalta ainda a aproximação entre aluno, professor, escola e universidade.

\section{Cursos preparatórios para o vestibular}

Nos últimos anos ocorreu grande expansão dos cursos preparatórios para o vestibular. Dirigidos aos segmentos específicos da população, estes cursos têm o objetivo de promover maior oportunidade de acesso ao ensino superior (MITRULIS; PENIN, 2006). Para Whitaker e Fiamengue (2001) é correto pensar que o cursinho pré-vestibular é o local onde se aprende a fazer o vestibular. Pesquisas feitas por estes autores relacionando o tempo feito de cursinho e a aprovação no vestibular mostram que candidatos com um ou dois anos de cursinho apresentam maior sucesso de aprovação no vestibular.

Segundo Borges e Carnielli (2005), a educação oferecida nas escolas tanto de poder público quanto da iniciativa privada não é suficiente para garantir o sucesso do aluno no processo de seleção para os cursos de maior prestígio. Esta falta é complementada com cursos adicionais de línguas, informática e com cursos prepa- 
ratórios para o processo de seleção para o ensino superior. $\bigcirc$ financiamento dessa preparação para o ensino superior é feito pelos pais. São custos altos e viáveis apenas aos pais de maior poder aquisitivo.

Para Domingues, Toschi e Oliveira (2000), existe uma contradição para a preparação do aluno, pois a LDB n9394/96 (BRASIL, 1996) pede uma flexibilidade do ensino, com base na interdisciplinaridade do conteúdo, mas contrastando com essa exigência, o vestibular, na maioria das universidades, padroniza a diversidade. Tal fato, segundo o autor, ocorre porque as matrizes curriculares desse exame são disciplinares. Bocchetto (2003) ainda ressalta que os exames vestibulares passaram a exigir conhecimentos cada vez mais específicos do ensino superior em suas questões. Os Cursos pré-vestibulares, segundo Mitrulis e Penin (2006), são cursos com finalidade lucrativa, que se dirigem aos segmentos mais favorecidos da população, e que aumentam o caráter seletivo do ensino superior.

Algumas formas alternativas de cursos preparatórios para o vestibular, direcionados para jovens carentes que não têm condição financeira para arcar com despesas de um cursinho, vêm sendo observadas. São cursos pré-vestibulares comunitários (CPVCs), a partir de projetos comunitários coordenados por ONGs (organizações não governamentais) locais ou associações de moradores, onde os docentes são recrutados na própria comunidade. Estes cursos também provêm de iniciativa de instituições filantrópicas de grupos ativos da sociedade civil, como igrejas, operando em seus espaços físicos, ou de escolas públicas ou privadas em horários cedidos. Os docentes são profissionais voluntários, estagiários e licenciados de faculdades públicas e privadas (CARVALHO, 2006).

\section{O ensino superior}

ensino superior brasileiro passou por um acentuado crescimento quantitativo nas últimas três décadas, o qual é caracterizado pelo aumento do número de instituições, de matrículas, de cursos e de funções docentes. $\bigcirc$ grande aumento no número de matrículas é decorrente da expansão do ensino médio acelerado nos últimos anos. Grande parte desse crescimento foi atendido e patrocinado pelo segmento privado. A rede pública, especialmente instituições federais, cresceram em ritmo mais lento comparado ao setor privado (MARTINS, 2000).

Aberto aos concluintes do ensino médio e aprovados no vestibular, o ensino superior, segundo Mitrulis e Penin (2006), deve ser acessível a todas as pessoas no decorrer da vida, sendo acessível a qualquer pessoa que tenha completado satisfatoriamente a educação básica.

Em pouco mais de 30 anos o ensino superior no Brasil passou por intensas transformações em sua morfologia, passando de instituições de pequeno porte, voltadas basicamente para atividades de transmissão de conhecimento, com corpo docente fracamente profissionalizado, para um quadro com complexas redes de estabelecimentos, que suporta tamanhos variados e absorve hoje, 2,1 milhões de alunos matriculados na graduação e aproximadamente 78 mil alunos de pós-graduação strictu senso, e que cobre todas as áreas do conhecimento (MARTINS, 2000; PINTO, 2004). 


\section{Desempenho dos estudantes universitários: metodologias didáticas adotadas pelos professores e formas de avaliação}

Primi, Santos e Vendramini (2002), analisando as correlações existentes entre medidas de inteligência fluida (que se referem às operações mentais que uma pessoa utiliza quando enfrenta situações relativamente novas, nas quais os conhecimentos habituais não são suficientes) e inteligência cristalizada (a qual se refere à extensão e à profundidade do conhecimento cultural adquirido e a capacidade de sua efetiva aplicação, referindo-se a um estoque organizado de conhecimento declarativo e também ao conhecimento de procedimentos de ação para situações conhecidas), verificaram a importância destas no processo de desenvolvimento acadêmico em universitários de alguns cursos (medicina, engenharia, matemática, pedagogia, letras, [...]), e constataram que, dependendo do curso considerado, diferentes habilidades emergem como mais importantes, e que o tipo de inteligência considerada mais importante para o desenvolvimento acadêmico vai depender do curso analisado.

Uma relação entre as dimensões da vivência acadêmica dos alunos universitários e o seu rendimento escolar é a que assume maior importância na explicação do rendimento dos alunos. Mas cabe acrescentar as variáveis mais decisivas para o rendimento acadêmico, como a base de conhecimento para o curso, adaptação ao curso, e percepção das competências cognitivas (SANTOS; ALMEIDA, 2001).

A aprendizagem universitária está associada ao aprender a pensar, e ao aprender a aprender. A metodologia utilizada pelo professor, ou seja, como o professor ajuda seu aluno a pensar com os instrumentos conceituais e os processos de investigação da ciência, são fundamentais neste processo (LIBÂNEO, 2002).

A forma de avaliação utilizada pelo professor é um meio importante para analisar o grau de compreensão do conteúdo exposto pelo aluno. Para Oliveira e Santos (2005), a nota ocupa um lugar de destaque na vida de qualquer estudante, principalmente dos estudantes universitários que consideram a nota o fundamental. A avaliação representa uma forma de quantificação do conhecimento do aluno, transformado em nota. A nota tem função administrativa, e funciona como instrumento de poder na relação professor e aluno.

As maneiras de avaliação devem ser diversificadas, a fim de atingir a diversidade de alunos, e suas diferentes formas de expressar o conhecimento adquirido (OLIVEIRA; SANTOS, 2005).

\section{Ensino superior: o aluno trabalhador}

Segundo Zago (2006), a expansão quantitativa do ensino superior brasileiro não beneficiou a população de baixa renda, que depende essencialmente do ensino público, e a polarização do ensino pago não reduziu as desigualdades entre grupos sociais.

As fortes transformações da sociedade ocorridas na década de 90 fizeram com que a procura por um elevado nível de escolarização aumentasse. Esse aumento 
decorrente dos processos de internacionalização da economia e do desenvolvimento tecnológico, bem como a globalização cultural, contribuíram para uma pressão pela obtenção do nível superior, visando a uma melhor colocação na sociedade contemporânea (MITRULIS; PENIN, 2006).

Para Martins (2002), com as exigências de um mercado de trabalho globalizado, o sistema de ensino superior tem posição estratégica e fundamental no processo de modernização do país, formando profissionais capacitados e qualificados cientificamente, para atender às diversas e cada vez mais complexas demandas tanto do setor público quanto do setor privado.

Pesquisas atuais mostram que a escolha do curso superior está fortemente ligada ao contexto social do aluno. Para Zago (2006), os jovens, provenientes de extratos inferiores da sociedade que chegam ao ensino superior, optam geralmente por cursos noturnos. Estes jovens agora têm um outro obstáculo, trabalhar em um período para pagar suas despesas e, algumas vezes, as de suas famílias, e estudar em outro período. Este tempo investido no trabalho como forma de sobrevivência impõe limites acadêmicos; como, por exemplo, participar de atividades extra-curriculares (seminários, palestras).

Programas de inclusão de alunos carentes em universidades privadas através de bolsas financiadas pelo governo demonstram, ao mesmo tempo, um processo de inclusão/exclusão destes, pois não basta fornecer uma bolsa de isenção de pagamento de anvidades, porque estes alunos precisam de verba para transporte, material de estudo, alimentação. E como não só de "pão vive o ser humano", torna-se necessário, também, que seja impulsionado o acesso aos equipamentos culturais como o cinema, teatro, bibliotecas e museus e outras oportunidades de intercâmbio, tendo em vista ampliar as formas de sociabilidade prazerosa e gratuita entre estes estudantes (DAUSTER, 2001).

Estudo e trabalho já não são atividades excludentes; ao contrário, o estudante que trabalha é uma realidade cada vez mais presente nas instituições de ensino superior no Brasil; a idade, e a condição socioeconômica são fatores diretamente relacionados para essa realidade. Alguns estudos mostram que no curso de biologia noturno, 74\% dos alunos trabalham e, no mesmo curso em período integral, $24 \%$. Isso porque mesmo recebendo ensino público gratuito, o aluno que provém de extratos sociais não muito favorecidos precisa contribuir no pagamento de suas próprias despesas, ou despesas de sua família, uma vez que estes podem possuir a sua própria família (CARDOSO; SAMPAIO, 1994).

\section{Metodologia}

trabalho foi desenvolvido com acadêmicos do quarto ano do Curso de Ciências Biológicas Bacharelado e do quinto ano de Ciências Biológicas Licenciatura de uma universidade pública, na região oeste do Paraná.

Foram analisados os cinco primeiros colocados no concurso vestibular 2003/ 2004, de cada curso, assim como os cinco últimos de cada curso. Foram analisadas as posições finais que cada aluno ocupa, descartando os candidatos aprovados que desistiram da vaga. Para melhor definição da amostra e elaboração precisa do ques- 
tionário foram realizadas pequenas entrevistas com os alunos dos cursos de ciências biológicas licenciatura e bacharelado, a fim de estabelecer um parâmetro de comparação do desenvolvimento dos alunos desde o início do curso, visando sempre a estabelecer uma relação com a colocação no vestibular.

Os dados das colocações dos acadêmicos aprovados foram levantados junto à pró-reitoria de graduação desta universidade.

Para estabelecermos possíveis causas do desempenho destes alunos no decorrer do curso, um questionário foi aplicado (anexo 1). Para Faria (1984), a principal vantagem do uso do questionário é poder atingir um universo muito maior que a entrevista, além da possibilidade de submeter todos os pesquisados aos mesmos estímulos. Entretanto, para Marconi e Lakatos (1990), o questionário apresenta algumas desvantagens, pois somente uma pequena porcentagem dos questionários é devolvida ao pesquisador e um número grande de perguntas apresenta-se sem resposta. A dificuldade de compreensão das questões por parte dos informantes e a impossibilidade de ajudá-los, assim como a devolução tardia do mesmo, também são algumas limitações do questionário.

Após a aplicação desse instrumento, as respostas foram analisadas através de uma análise quantiqualitativa. A pesquisa qualitativa tem caráter exploratório, que se baseia em pequenas amostras e permite melhor compreensão do contexto do problema, expondo a perspectiva das pessoas estudadas envolvendo uma descrição acurada do fenômeno e do cenário social pesquisado, não somente a partir do ponto de vista das pessoas envolvidas, mas também dos pesquisadores (OLIVEIRA, 1997). Quanto à análise quantitativa trata-se, segundo Lima (2003), de uma metodologia que apresenta objetividade, rigor, regras de procedimentos e representatividade estatística, levando-os a suportar formulação de leis e explicações gerais, em função da regularidade com que é empregada a metodologia quantitativa.

Para avaliar as notas obtidas nas disciplinas durante o curso foram analisados os históricos escolares informais dos acadêmicos, os quais foram cedidos pelos próprios. Para melhor descrever os resultados foram estabelecidos padrões de notas divididos em três classificações: razoável, bom, ótimo, sendo considerado o resultado de 6,0 a 7,0 como razoável, de 7,0 a 8,5 como bom, e de 8,5 a 100 como ótimo.

\section{Análise da turma 1: Ciências Biológicas Licenciatura}

Existe um contraste muito grande entre as duas turmas analisadas, e os resultados refletem essa diferença da realidade enfrentada por cada uma das turmas. Dois cursos com princípios básicos iguais, mas com enfoques um tanto quanto diferentes, também refletem características diferentes. Para uma melhor análise dos resultados coube fazê-los de forma separada.

curso de ciências biológicas é ofertado nesta universidade no período noturno, com duração de cinco anos, e tem como objetivo a formação de profissionais da educação em ciências biológicas para atuar no ensino fundamental e médio, além da condição de biólogo. Uma característica interessante do ensino superior brasileiro é 
que mais de $50 \%$ do total de matriculas existentes $(4,1$ milhões de matriculas) no ensino superior estão no período noturno. Porém os cursos noturnos, que representam a maior parcela no número de matrículas, foram criados há menos de 50 anos, visando a atender as camadas trabalhadoras da sociedade (BARREIRO; TERRIBILI FILHO, 2007).

\section{Análise do questionário}

Foram aplicados dez questionários nesta turma, direcionados para os cinco primeiros colocados no vestibular, e os cinco últimos colocados. Os cinco primeiros alunos foram identificados como Grupo licenciatura 1 (GL1), e os cinco últimos como Grupo licenciatura 2 (GL2).

O curso de ciências biológicas licenciatura o GL1 apresentou condições consideradas peculiares em relação ao grupo denominado como GL2. Para melhor visualização estas diferenças foram esquematizadas na tabela 1. Estas condições são determinadas pela faixa etária entre 22 e 25 anos, menor que a apresentada pelo GL2, na qual se encontram entre 24 e 36 anos. Em relação à existência de alunos com filhos, no GL1 nenhum dos entrevistados respondeu ter filhos, contrastando com o GL2 onde dois indivíduos tem filhos. Essa condição pode ser reflexo da idade dos alunos do GL2, assim como o estado civil destes alunos, onde três alunos se declararam casados, condição também adversa em relação ao GL1, onde todos os indivíduos se declararam solteiros. Ocorreu na amostra um predomínio do sexo feminino, sendo $70 \%$ da amostra composta por mulheres. Os cursos de licenciatura, assim como os cursos relacionados com a saúde têm uma procura bastante grande por parte das mulheres (BRAGA; PEIXOTO; BOGUTCHI, 2001).

A preparação destes alunos para o vestibular também foi analisada através do questionário desde a sua formação básica até o curso preparatório para o vestibular. Quando o GL1 foi questionado sobre se estudou em escola pública em algum ano da sua formação básica, apenas um aluno respondeu ter feito todo esse período em escola particular, dois alunos responderam ter feito apenas o último ano do ensino médio (terceirão) em escola privada, e dois alunos disseram ter feito toda a sua formação básica em escola pública. Deste grupo apenas um aluno respondeu não ter feito curso pré-vestibular. Quando estas mesmas questões foram aplicadas ao GL2, todos os entrevistados responderam ter feito todo o ensino fundamental e médio em escola pública e, quanto ao curso preparatório, responderam não o terem feito, ou fizeram apenas 15 ou 30 dias (curso pré-vestibular denominado como superintensivo). Segundo Pinho (2001), a preparação propiciada por escolas públicas de ensino médio é insuficiente para garantir o sucesso na competição por uma vaga no vestibular. $\bigcirc$ autor ainda ressalta que alunos com preparações "mistas", parte em escola pública, parte em escola privada, escolhem cursos concorridos obtendo resultados intermediários.

Em relação ao desempenho durante o ensino médio, todos os alunos dos dois grupos consideraram seu desempenho como bom ou ótimo. Um passado de bons resultados no ensino médio contribui para o acesso ao ensino superior (ZAGO, 2006). Somente um aluno da amostra estudada (dos dois grupos) apresentou $100 \%$ de aprovação nas disciplinas oferecidas pelo curso de ciências biológicas. Este mesmo aluno também foi o único a responder que toda a sua formação básica foi realizada em escola privada. É de conhecimento geral a formação deficiente propiciada pelas 
escolas públicas no Brasil, essa realidade tem se mostrado cada vez mais evidente na disputa por uma vaga no ensino superior, e conseqüentemente, pela permanência nesse grau de ensino, pois estes alunos quando conseguem passar nas provas de vestibular, mostram muitas dificuldades na realização do curso superior, as quais são atribuídas, em parte, à sua deficiente formação básica (NEVES, 2002; ZAGO, 2006).

Os cursos preparatórios para o vestibular parecem ter um papel importante na aprovação. $\bigcirc$ curso preparatório para o vestibular de cunho lucrativo, objetiva promover maior oportunidade de acesso ao ensino superior (MITRULIS; PENIN, 2006), e não é errado pensar que o cursinho pré-vestibular é onde se aprende a fazer o vestibular (WHITAKER; FIAMENGUE, 2006).

Quando os alunos foram questionados quanto à aprovação no primeiro vestibular e se gostariam de ter feito outro curso ao invés de biologia, apenas dois alunos do GL1 responderam que passaram no primeiro vestibular que prestaram, no caso para biologia, e apenas um aluno respondeu que a sua primeira opção sempre foi pela biologia. Os outros alunos analisados gostariam de ter feito outro curso, mas disseram que a falta de sucesso no vestibular ou o medo de não passar os fizeram optar pela biologia. Quanto ao GL2, três alunos disseram ter passado no primeiro vestibular que prestaram, e apenas um respondeu sempre ter optado pela biologia. Ciências biológicas, dentre os cursos de menor prestígio social é considerado o de maior prestígio devido à sua proximidade com medicina, e outros cursos relacionados com a área da saúde, o que faz com que seja procurado por candidatos que já tentaram vestibulares para estes cursos sem obterem sucesso (WHITAKER; FIAMENGUE, 2001).

Todos os alunos entrevistados afirmam ter se identificado com o curso, com exceção de um aluno do GL1, que disse ter tido apenas afinidade com algumas disciplinas. E quanto à questão das expectativas em relação ao curso terem sido supridas no decorrer do mesmo, este mesmo aluno foi o único a responder que não, e pretendia fazer outro curso após o termino do curso de biologia. Claro que se tratando de uma analise qualitativa devemos analisar os casos de desnível isolados, como neste caso em que o aluno declara não se ter identificado completamente com o curso, e ainda ressalta que pretendia fazer outro curso superior e não ter certeza se conseguiria terminar o curso de ciências biológicas licenciatura. Esse relato talvez justifique o seu desempenho considerado razoável, o qual apresentou muitas reprovações e médias razoáveis nas disciplinas em que conseguiu aprovação. Para Santos e Almeida (2001), a realização do acadêmico com o curso de graduação é uma das variáveis mais decisivas para a explicação no rendimento escolar.

Quando o GL1 foi questionado se trabalhava, se tinha filhos e qual a sua participação no sustento da família, todos responderam que não têm filhos, e apenas um aluno respondeu que nunca trabalhou inclusive no período em que estava cursando a faculdade. Todos os outros alunos responderam que trabalharam em pelo menos uma etapa do curso, e estes apesar de não serem responsáveis pelo sustento integral da família, eram responsáveis pelo orçamento parcial desta, pois eram pelo menos responsáveis por suas próprias despesas. Quando as mesmas questões foram aplicadas ao GL2, todos os estudantes responderam que trabalharam durante todos os anos em que estavam cursando a faculdade, com exceção de dois alunos que pararam de trabalhar no 
último ano da faculdade, todos os outros conciliaram faculdade e trabalho durante todo o período do curso. Dois dos indivíduos disseram ter filhos, coincidentemente os dois alunos tem dois filhos, sendo que um destes alunos do sexo masculino é responsável pelo sustento integral de sua família. Quanto aos outros alunos todos são responsáveis parciais, pois são responsáveis pelo menos por suas próprias despesas.

Os alunos trabalhadores são uma realidade cada vez mais freqüente nos cursos superiores brasileiros, e se intensifica quando essa análise é feita nos cursos do período noturno, pois os alunos que provêm de extratos sociais não muito favorecidos precisam contribuir com o pagamento de suas próprias despesas, ou quando este já é chefe de família, precisa contribuir com o sustento integral de sua família (CARDOSO; SAMPAIO, 1994). Isso se confirma na amostra analisada, apenas um aluno disse não ter trabalhado no período em que cursava a faculdade, todos os outros analisados trabalharam em pelo menos um período enquanto cursavam a universidade. $\bigcirc$ fato de os alunos trabalharem enquanto cursam a faculdade gera muitas limitações dentro do curso como, por exemplo, participar de atividades extracurriculares como palestras, seminários, congressos (ZAGO, 2006). Limitações relacionadas com a disponibilidade de tempo para estudar em períodos em que não estão na universidade, pois na maioria das situações os alunos saem direto do trabalho para as aulas na universidade, o cansaço e as outras preocupações do dia-a-dia parecem ter papel fundamental no desenvolvimento de atividades e atenção durante as aulas (BARREIRO; TERRIBILI FILHO, 2007).

Os alunos também foram questionados em relação aos planos após o termino do curso. A maioria dos alunos questionados pretende prestar concursos públicos na área ou não, para começar a trabalhar imediatamente (os que não estão trabalhando e/ou não estão trabalhando na área), e ainda responderam que desejam continuar estudando fazendo pós-graduação (especialização, mestrado) apenas um aluno pretende fazer outro curso de graduação. A tabela 1 mostra um comparativo entre os dados obtidos para o GL1 e o GL2.

desempenho destes alunos durante o curso mostrou-se relativo, pois os alunos que declaram terem trabalhado durante o curso apresentam reprovações. Entretanto essas reprovações variam entre uma e mais de cinco reprovações. È possível que outros fatores tenham contribuído para esse desempenho, como a didática utilizada pelos professores (CUNHA; BRITO; CICILLINI, 2004), a afinidade pelas disciplinas, porém o fato de estes alunos trabalharem parece ser um limitante quanto ao desempenho no curso. Um comparativo entre o GL1 e o GL2 (tabelal) mostra que de maneira geral os últimos colocados mantêm desempenho menor (ruim) em relação aos primeiros colocados, os quais apesar de mostrarem reprovações são em número menor, e as médias nas disciplinas que obtiveram aprovação são maiores.

\section{Análise do histórico acadêmico dos entrevistados}

Grupo licenciatura 1: quanto ao desempenho em termos de notas obtidas nas disciplinas durante o curso, os alunos desse grupo apresentaram uma média considerada boa (entre 7,5 e 8,5), apenas um aluno apresentou 100\% de aprovação nas disciplinas, sem apresentar nenhuma reprovação. Um aluno apresentou apenas uma reprovação, mantendo boas médias nas outras disciplinas. Dois alunos apresentaram duas reprovações, entretanto mantendo 
médias razoáveis a boas (entre 6,0 e 7,5) nas outras disciplinas. Um aluno apresentou mais que cinco reprovações e notas consideradas razoáveis nas outras disciplinas.

Grupo licenciatura 2: apenas um aluno apresentou duas reprovações, mantendo boas médias nas outras disciplinas. Um aluno apresentou três reprovações, obtendo boas médias quanto às outras disciplinas. Três alunos apresentaram mais que cinco reprovações, mantendo médias razoáveis em relação às outras disciplinas em que foram aprovados.

grupo 1 mostra um desempenho melhor em relação ao grupo 2, mesmo com reprovação o GL1 de maneira geral mostra um desempenho melhor que o GL2 nas disciplinas. Isso parece ser reflexo da idade do GL2, maior que a GL1, e conseqüentemente uma vida mais estruturada, com filhos, emprego obrigatoriamente.

Tabela 1 - Comparativo dos resultados obtidos nos dois grupos da modalidade licenciatura do curso de Ciências Biológicas.

\begin{tabular}{|l|c|c|}
\hline \multicolumn{3}{|c|}{ Comparação entre o Grupo 1 e 2 Ciências Biológicas Licenciatura } \\
\hline Faixa etária & GL1 & GL2 \\
\hline Sexo & 22 a 25 anos & 24 a 36 anos \\
\hline$N^{\circ}$ de alunos com filhos & 4 @\&,1B\& & 3 @\&, 2 B\& \\
\hline$N^{\circ}$ de alunos casados & 00 & 02 \\
\hline$N^{\circ}$ de alunos trabalhadores & 00 & 03 \\
\hline Formação inteiramente em escola pública & 04 & 05 \\
\hline Desempenho no ensino médio & 02 & 05 \\
\hline Preparação para o vestibular (cursinho) & Bom/Ótimo & Bom/Ótimo \\
\hline No de alunos com reprovação & 04 & 03 \\
\hline Desempenho durante o curso & Bom/Ótimo & Razoável/Bom \\
\hline
\end{tabular}

Fonte: as Autoras (2007).

\section{Análise da turma 2: Ciências Biológicas Bacharelado Análise do questionário.}

Foram aplicados dez questionários nesta turma, divididos entre os cinco primeiros colocados no vestibular e os cinco últimos. Também nesta turma os cinco primeiros foram identificados como Grupo bacharelado 1 (GB1), e os cinco últimos como Grupo bacharelado 2 (GB2).

Os alunos do GB1 apresentaram idade entre 21 e 26 anos, com predomínio da idade de 21 anos (quatro indivíduos). Todos apresentaram estado civil solteiro, e uma peculiaridade deste grupo é que todos os indivíduos são do sexo feminino. O GB2 apresentou idade entre 21 e 22 anos, e todos os alunos desse grupo apresentaram estado civil solteiro. Três indivíduos desse grupo são do sexo masculino e dois do sexo feminino. Como já mencionado na análise da turma anterior, existe uma maior procura por parte do sexo feminino nos cursos relacionados à saúde, ou que se aproxima desta (BRAGA; PEIXOTO; BOGUTCHI, 2001), a amostra analisada confirma esta observação. 
Quando os alunos foram questionados em relação à aprovação no primeiro vestibular que prestaram, apenas um aluno do GB1 disse não ter passado no primeiro vestibular que prestou. Dois alunos deste grupo disseram que gostariam de ter feito outro curso. Quanto ao GB2, somente um aluno disse não ter passado no primeiro vestibular que prestou, e ainda respondeu sempre ter optado pala biologia; apenas um aluno disse que gostaria de ter feito outro curso, mais não justificou a opção pela biologia.

Nenhum dos alunos entrevistados nos dois grupos disse ser responsável pelo sustento da família, seja ele parcial ou integral. Nos dois grupos somente dois alunos responderam que trabalhavam quando prestaram vestibular, e apenas um aluno, dentre todos os entrevistados disse ter trabalhado durante o curso. Todos os entrevistados responderam não ter filhos.

Talvez os dados mais interessantes a serem analisados nesta amostra seja o fato de que todos os entrevistados tiveram integral, ou parte da formação básica em escola privada. Dois alunos do GB1 responderam nunca terem estudado em escola pública durante a sua formação básica (ensino fundamental e médio), os outros três entrevistados deste grupo disseram ter tido uma formação mista, parte em escola pública parte em escola privada. No GB2 ocorreu situação semelhante, onde todos os entrevistados disseram ter feito parte da formação básica em escola privada. Como descrito por Neves (2002), a formação básica tem papel importante no êxito em exames para o ingresso no ensino superior, e posteriormente no desenvolvimento desse curso.

Zago (2006), afirma que alunos que provêm de escolas privadas apresentam maiores chances na disputa por uma vaga no ensino superior, levando em consideração a melhor qualidade de ensino na escola privada, e ainda ressalta que a condição socioeconômica dos pais influencia na formação dos filhos, pois estes possuem condições econômicas para investir na formação deles. Entretanto Pinho (2001) ressalta um dado interessante que revela que alunos que fazem parte dos estudos em escola pública e parte em escola privada apresentam resultados de intermediários a bons na disputa por uma vaga em cursos considerados concorridos.

Todos os alunos classificaram o seu desempenho durante o ensino médio como bom ou ótimo. Quando os entrevistados foram questionados sobre se haviam feito algum curso preparatório para o vestibular, somente um aluno do GB1 respondeu que não, quanto ao GB2, três alunos responderam ter feito um curso preparatório para o vestibular. Segundo Borges e Carnielli (2005), a educação oferecida nas escolas tanto no poder público quanto pela iniciativa privada não é suficiente para garantir o sucesso no vestibular, em muitos cursos ditos de maior concorrência. Essa lacuna é complementada com cursos adicionais de línguas, informática e com cursos preparatórios para o vestibular.

Todos os alunos entrevistados foram unânimes ao responder que se identificaram com o curso, mas algumas ressalvas foram feitas quando as expectativas em relação ao curso foram questionadas. No GBI um aluno disse que algumas de suas expectativas não foram supridas, o que se repetiu no GB2, onde um aluno disse ter parte de suas expectativas não correspondidas. A realização acadêmica pode ser um reflexo do rendimento escolar do universitário, e esta realização com o curso que segundo Santos e Almeida (2001), assumem maior importância na explicação do rendimento dos alunos. 
Quanto aos planos após o termino do curso, todos os alunos pretendem continuar fazendo uma pós-graduação (mestrado/doutorado). No GB1 um aluno respondeu que deseja cursar a licenciatura antes de fazer a pós-graduação, e dois alunos responderam ainda que pretendem também prestar concursos na área de formação. No GB2 todos responderam desejar fazer uma pós-graduação, mas pensam em trabalhar na área também, um aluno respondeu que pretende fazer licenciatura depois que concluir o bacharelado, e antes de fazer pós-graduação. A tabela 2 mostra um comparativo entre os dados obtidos no GB1 e GB2.

\section{Análise do Histórico Escolar}

Grupo bacharelado 1: Nenhum dos alunos desse grupo apresentaram reprovação, todos apresentaram boas médias ( entre 7,5 e 8,5) nas disciplinas cursadas.

Grupo bacharelado 2: Dois alunos apresentaram 100\% de aprovação nas disciplinas cursadas, com médias consideradas boas (entre 7,5 e 8,5). Um aluno apresentou uma reprovação, mantendo médias boas nas disciplinas em que foi aprovado. Dois alunos apresentaram duas reprovações mantendo médias razoáveis á boas $(6,0$ e 7,5 ; e 7,5 a 8,5$)$ nas outras disciplinas que obtiveram aprovação.

Também nesta turma o GB1 apresentou melhor desempenho que o GB1, entretanto outros motivos parecem estar relacionados como a identificação com o curso, e a preparação básica, a qual realizou grande parte em escola privada. Isso também pode ser justificado com a falta de identificação de alguns indivíduos com o curso, ou com algumas matérias do mesmo.

Tabela 2 - Comparativo dos resultados obtidos para os dois grupos na modalidade bacharelado para o curso de Ciências Biológicas.

\begin{tabular}{|c|c|c|}
\hline \multicolumn{3}{|c|}{ Comparação entre o Grupo 1 e 2 Ciências Biológicas Bacharelado } \\
\hline & GB 1 & GB2 \\
\hline Faixa etária & 21 à 26 anos & 21 à 22 anos \\
\hline Sexo & $5 @ \&$ & 2@\&, 3B\& \\
\hline$N^{\circ}$ de alunos com filhos & 00 & 00 \\
\hline $\mathrm{N}^{\circ}$ de alunos casados & 00 & 00 \\
\hline $\mathrm{N}^{\circ}$ de alunos trabalhadores & 00 & 00 \\
\hline Formação inteiramente em escola pública & 00 & 00 \\
\hline Desempenho no ensino médio & Bom/Ótimo & Bom/Ótimo \\
\hline Preparação para o vestibular (cursinho) & 04 & 03 \\
\hline $\mathrm{N}^{\circ}$ de alunos com reprovação & 00 & 03 \\
\hline Desempenho durante o curso & Bom/Ótimo & Bom/Ótimo \\
\hline
\end{tabular}

Fonte: as Autoras (2007).

Os resultados das duas turmas são muito contrastantes quando comparados. Os grupos de cada turma apresentam grandes diferenças, as quais parecem estar relaci- 
onadas ao fato de os alunos da licenciatura no período noturno trabalharem, ou terem trabalhado em grande parte do curso, outro ponto importante a ser citado é o fato de a maioria dos alunos da licenciatura terem feito exclusivamente a formação básica em escola pública. A idade dos alunos também parece ser um dado atenuante para o desenvolvimento durante o curso, pois conseqüentemente estes alunos já possuem uma vida mais estruturada com família, filhos, emprego.

\section{Considerações finais}

Realmente parece ser possível relacionar a classificação no vestibular com o desenvolvimento durante o curso, os resultados das médias em ambas as turmas demonstram isso, mesmo na turma do bacharelado onde ocorreu um desnível mais discreto, também ocorrem diferenças entre o Grupo 1 e o Grupo 2. Claro que para uma afirmação mais precisa, uma analise minuciosa seria necessária, analisando também outros fatores que também poderiam estar relacionados com este desempenho dos indivíduos como, por exemplo, socioeconômicos, formas de aprendizados diferenciados, fatores cognitivos de cada aluno, se a didática utilizada por cada professor atinge todos os públicos de alunos, etc.

Os alunos com formação básica feita exclusivamente em escola pública parecem ter mais dificuldade durante o curso. Essa situação se mostrou muito nítida na análise dos grupos da licenciatura.

vestibular parece ter papel relevante quanto à aprovação no vestibular, pois a maioria dos entrevistados respondeu ter feito alguma preparação para a prova do vestibular.

fato de os alunos residirem com os pais ou com amigos em república não parece ter muita relevância no desempenho durante o curso, pois alunos que responderam morar sozinho ou com a família mostram desempenhos semelhantes.

O desempenho dos alunos que trabalham parece ser afetado, em relação aos alunos que não trabalham, suas médias são relativamente mais baixas e conseqüentemente algumas reprovações. A identificação com o curso parece ser relevante quanto ao desempenho no curso. Esse pode ser um indicativo entre outros do bom desempenho dos alunos do bacharelado.

Existem pontos contrastantes entre as duas turmas analisadas, e pesquisas mais abrangentes são necessárias para avaliar a grande diferença no desempenho entre as modalidades de licenciatura e bacharelado do curso de ciências biológicas. 


\section{Referências}

BACCHETTO, J. G. Cursinhos pré-vestibulares alternativos no município de São Paulo (1191 a 2000): a luta pela igualdade no acesso ao ensino superior. 2003. Dissertação (Mestrado em Educação) - Faculdade de Educação, Universidade de São Paulo, São Paulo, 2003.

BARREIRO, I. M. F.; TERRIBILI FILHO, A. Educação superior no período noturno no Brasil: políticas, intenções e omissões. Ensaio: avaliação e políticas públicas em educação, Rio de Janeiro, v. 15, n. 54, p. 81 -102, jan./mar. 2007.

BRAGA, M. M.; PEIXOTO, M. C. L.; BOGUTCHI, T. F. Tendências da demanda pelo ensino superior: estudo de caso da UFMG. Cadernos de Pesquisa, São Paulo, n. 113, p. 129-152, jul. 2001.

BORGES, J. L. G.; CARNIELLI, B. L. Educação e estratificação social no acesso a universidade pública. Cadernos de Pesquisa, São Paulo, v. 35, n. 124, p. 113 139, jan./abr. 2005.

BRASIL. Lei no 9.394, de 20 de dezembro de 1996. Estabelece as diretrizes e bases da educação nacional. Diário Oficial [da República Federativa do Brasil], Brasília, DF, 23 de dezembro de 1996. Disponível em: <www.planalto.gov.br>. Acesso em: 11 mar. 2008.

CARDOSO, R. C. L.; SAMPAIO, H. Estudantes universitários e o trabalho. Revista Brasileira de Ciências Sociais, São Paulo, n. 26, p. 30-50, 1994.

CARVALHO, J. C. B. Os cursos pré-vestibulares comunitários e seus condicionantes pedagógicos. Cadernos de Pesquisa, São Paulo, v. 36, n. 128, p. 299-326, maio/ago. 2006.

CUNHA, A. M. O.; BRITO, T. T. R.; CICILlINI, G. A. Dormi aluno(a)... Acordei professor(a): interfaces da formação para o exercício do ensino superior. Políticas de Educação Superior, [S. I.], n. 11, p. 1-15, 2004.

DAUSTER, T. "Bolsistas" e "elite": tensão e mediação na construção diferencial de identidades de estudantes universitários. In: REUNIÃO ANUAL DA ASSOCIAÇÃO BRASILEIRA DE ANTROPOLOGIA, 23., 2001, Caxambu. Anais... Gramado, RS, 2001.

DOMINGUES, J. J.; TOSCHI, N. S.; OLIVEIRA, J. F. A reforma do ensino médio: a nova formulação curricular e a realidade da escola pública. Educação \& Sociedade, Campinas, SP, v. 21, n. 70, p. 63-79, abr. 2000.

FARIA, A. N. Organização e métodos. Rio de Janeiro: Livros Técnicos e Científicos, 1984.

LEITE, D. Sistemas de avaliação das instituições de ensino superior no Brasil. In: SOARES, M. S. A. (Org.). A educação superior no Brasil. Brasília, DF: Coordenação e Aperfeiçoamento de Pessoal de Nível Superior, 2002.

LIBÂNEO, J. C. Reflexidade e formação de professores: outra oscilação do pensamento pedagógico brasileiro? In: PIMENTA, S. G.; GHEDIN, E. Professor reflexivo no Brasil: gênese e crítica de um conceito. São Paulo: Cortez, 2002. 
LIMA, M. C. Monografia: a engenharia da produção acadêmica. São Paulo: Saraiva, 2003. MARCONI, M. A.; LAKATOS, E. M. Técnicas de pesquisa. 2. ed. São Paulo: Atlas, 1990. MARTINS, C. B. O ensino superior brasileiro nos anos 90. São Paulo em Perspectiva, São Paulo, v. 14, n. 1, p. 41-60, 2000.

MITRULIS, E.; PENIN, S. T. S. Pré-vestibulares alternativos: da igualdade a equidade. Cadernos de Pesquisa, São Paulo, v. 36, n. 128, p. 269-298, maio/ago. 2006.

NEVES, E. B. A estrutura e o funcionamento do ensino superior no Brasil. In: SOARES, M. S. A, (Org.). A educação superior no Brasil. Brasília, DF: Coordenação e Aperfeiçoamento de Pessoal de Nível Superior, 2002.

OLIVEIRA, K. L.; SANTOS, A. A. A. Compreensão em leitura e avaliação da aprendizagem em universitários. Psicologia: reflexão e crítica, Porto Alegre, RS, v. 18, n. 1, p. 118-124, jan./abr. 2005.

OLIVEIRA, S. Metodologia científica: projetos de pesquisa, TGI, TCC, monografias, dissertações e teses. São Paulo: Pioneira, 1997.

PINHO, A. G. Reflexões sobre o papel do concurso vestibular para as universidades públicas. Estudos Avançados, São Paulo, v. 15, n. 42, p. 353-362, maio/ago. 2001.

PINTO, J. M. R. O acesso à educação superior no Brasil. Educação \& Sociedade, Campinas, SP, v. 25, n. 88, p. 727-756, out. 2004. Edição especial.

PRIMI, R.; SANTOS, A. A. A.; VENDRAMINI, C. M. M. Habilidades básicas e desempenho acadêmico em universitários ingressantes. Estudos de Psicologia, Natal, RN, v. 7, n. 1, p. 47-55, 2002.

SANTOS, L.; ALMEIDA, L. S. Vivências acadêmicas e rendimento escolar: estudos com alunos universitários do $1^{\circ}$ ano. Análise Psicológica, Lisboa, PT, n. 2, p. 205-217, 2001.

SCHLINCHTING, A. M. S.; SOARES, D. H. P.; BIACHENTTI, L. Vestibular seriado: análise de uma experiência em Santa Catarina. Psicologia e Sociedade, Porto Alegre, v. 16, n. 2, p. 114-126, maio/ago. 2004.

WHITAKER, D. A.; FIAMENGUE, E. C. Ensino médio: função do estado ou da empresa? Educação \& Sociedade, Campinas, SP, v. 75, p. 200-232, ago. 2001.

ZAGO, N. Do acesso à permanência no ensino superior, percursos de estudantes universitários de camadas populares. Revista Brasileira de Educação, Campinas, SP, v. 11, n. 32, p. 226-370, 2006.

Recebido em: 18/12/2007

Aceito para publicação em: 07/02/2008 